\title{
Hacia una ciencia de la vida mental Entrevista realizada en el 2007 por Renaud Persiaux a Stanislas Dehaene*
}

\author{
Traducción del francés al español de \\ Luis Alfonso Paláu-Castaño \\ Universidad Nacional de Colombia, Medellín, Colombia \\ laPalau@une.net.co
}

- Su lección inaugural en el Colegio de Francia se tituló "Hacia una ciencia de la vida mental", ¿por qué?

Primero, para inscribir mi proceder en la (ya) larga historia de la psicología; es la definición propuesta en el siglo XIX por William James, uno de sus padres fundadores. Segundo, porque yo creo que la psicología será uno de los nudos esenciales de una futura ciencia de la vida mental pluridisciplinaria. Esta tendrá por objetivo explicar cómo pensamos por medio de unas series de leyes sucesivas que tienen en cuenta diferentes aspectos que van desde la biología del cerebro hacia la dimensión cultural. El reto es llegar a establecer leyes de la psicología tan universales como las de la física. Para mí, es posible estudiar el pensamiento -aunque este sea subjetivo e íntimo-, de manera científica, especialmente porque sus características son ampliamente compartidas a través del mundo. Creo que cada una de nuestras representaciones mentales es también un objeto neuronal, incluso si las leyes de enlace entre los dos niveles todavía están por establecerse. En el laboratorio, nuestras investigaciones se articulan ya entre comportamiento, desarrollo del niño, neuropsicología, imagenografía cerebral...

- ¿Este proceder no es reduccionista por naturaleza?

No. No soy de los que propone, como la filósofa Patricia Churchland, una neurociencia eliminativista en la que la psicología desaparecería en provecho de una neurociencia pura que reduce todos los objetos a la biología. A la inversa, pienso que existen leyes de la psicología en tanto tales, completamente válidas a su nivel, al mismo título que las leyes de la lingüística y de la economía. Hay múltiples niveles de descripción de la extraordinaria complejidad del ser humano. Entre mejor se haya comprendido el nivel psicológico, más fácil será investigar sus bases neuronales.

Cómo citar: Paláu-Castaño, L. A. (2018). Hacia una ciencia de la vida mental. Entrevista realizada en el 2007 por Renaud Persiaux a Stanislas Dehaene. Ciencias Sociales y Educación, 7(14), 219-223. DOI: https://doi.org/10.22395/ csye.v7n14a11

Traducción retomada de: Dortier J.F. (dir.) (2012). El cerebro y el pensamiento. La nueva edad de las ciencias cognitivas (pp. 53-58). Auxerre: Sciences Humaines éditions.

Agradecemos a la editorial francesa Sciences Humnaines autorzar la publicación en español de la entrevista al psicólogo cognitivo experimental del Collège de France Stanislas Dehaene. Nota del editor.

Recibido: 15 de agosto del 2018.

Aprobado: 18 de octubre del 2018. 
Inversamente, los descubrimientos sobre el cerebro entrañan nuevas cuestiones de orden psicológico y nuevas teorías. Creo mucho en la interactividad entre las dos disciplinas.

- La psicología funcionalista planteaba que cualquier programa puede ser efectuado por el cerebro, de la misma manera que cualquier software puede funcionar sobre el soporte material del ordenador. ¿Por qué rechaza usted esta concepción?

Esta metáfora del cerebro computador, que se inspira y mantiene una dicotomía artificial muy rígida entre cerebro y pensamiento, es extremadamente limitada. El cerebro, de ninguna manera funciona, así. La mayor parte de las operaciones mentales reposan sobre redes cerebrales especializadas (para percibir las formas o los colores, por ejemplo). Mis investigaciones y las de mi esposa Ghislaine Dehaene-Lambertz han demostrado así que existen estructuras cerebrales organizadas para tratar el lenguaje hablado ya presentes en los bebés de dos meses. Por ejemplo, el área de Broca se activa en relación con otras regiones temporales cuando el niño escucha frases en su lengua materna.

- Y sin embargo, usted no parece acoger la noción de módulo innato...

No me gusta el término "innato", no le hace justicia a la complejidad de las relaciones entre biología y psicología. Ciertamente, existen estructuras precoces en el cerebro. Y sin embargo, no son "módulos" listos para ser empleados en el reconocimiento de rostros o en la lectura. Por el contrario, ellos maduran en la interacción con el entorno. Cuando por ejemplo, usted estudia los circuitos cerebrales de la lectura a través del mundo, ya sea que se utilice escritura alfabética o ideogramas, siempre son las mismas zonas las que se activan. La plasticidad del cerebro deja el sitio a la variable cultural.

- En su obra hay un término que usted retoma a menudo, el de código neural, ¿de qué se trata?

El código neural permite poner en relación las representaciones mentales y neuronales. De hecho, no hay un código único sino muchos diferentes según las regiones. Tomemos un ejemplo, el de la lectura. La codificación arranca desde la retina con algunos millones de fotorreceptores que detectan la presencia de luz en un punto dado. A partir de esa expansión, el cerebro logra reconstituir una representación de la palabra. ¿Cómo? Se piensa que interviene una jerarquía de representaciones visuales sucesivas. Se sabe que en el animal y en el hombre existen tales jerarquías, por ejemplo, para el reconocimiento de los rostros. Algunas neuronas responden a una persona dada, a veces con un importante nivel de abstracción. Investigadores de San Diego han identificado, por ejemplo, una neurona que codifica para la estrella de Hollywood Jennifer Aniston, ya se la 
vea de frente, de perfil, o de espaldas, que se escuche su voz o su nombre. No es una neurona única la que hace el trabajo, sino millones, incluso si la tecnología utilizada -el registro celular- solo permite detectar una a la vez. Se trata pues de una asamblea neuronal "Jennifer Aniston", constituida por aprendizaje y distribuida en numerosas regiones cerebrales, cada una aportando su ladrillo a una etapa precisa del reconocimiento visual.

\section{- ¿Cómo se puede comprender ese código?}

Una herramienta muy útil es la imagenografía por resonancia magnética (IRM) que utilizamos, por ejemplo, para comprender la lectura. Lo que es apasionante es que los resultados arrojados concuerdan con las observaciones del neurólogo Jules Déjerine del siglo XIX, que trabajaba con sujetos que padecían lesiones cerebrales. Las áreas que faltaban en los pacientes aléxicos son precisamente las que se activan con la lectura. A medida que comprendemos la codificación neural de los objetos mentales, nos volvemos capaces de invertir el procedimiento; partiendo de la actividad cerebral tratamos de deducir el contenido mental. De este modo, Bertrand Thirion y yo hemos mostrado que cuando uno imagina una letra (por ejemplo una X), la topografía de la activación en las áreas visuales reproduce la forma de esa letra. Pero si hacemos el camino inverso, si se parte de esta activación, se puede deducir el stimulus que imaginó el sujeto. Evidentemente hay numerosos límites, debidos incluso a la débil resolución actual, el método solo funciona para las configuraciones macroscópicas de actividad. Se puede por ejemplo, distinguir la percepción de un rostro de la de una casa puesto que los territorios corticales que corresponden están distantes al menos en un centímetro. Pero por el momento, como no se ha entrado aún en las regiones, no se puede ver la diferencia entre la palabra "casa" y la palabra "rostro".

- iLa ciencia alcanza la ficción! ¿Sería posible leer en los pensamientos?

En teoría, no encuentro argumento que se le pudiera oponer. Pero en la práctica, se requeriría unos productores de imágenes muchos más robustos que los que sabemos fabricar, y por supuesto un sujeto que colabore y permanezca perfectamente inmóvil. No necesitamos pues fantasmear; ningún Big Brother a la vista. De todas maneras, leer los pensamientos no es lo que nos interesa. Buscamos solamente comprender los mecanismos del pensamiento, la manera en que las áreas se articulan, cómo circula la información. Encontrar una ley de enlace psiconeuronal podría permitir, por ejemplo, comprender mejor el estado de los pacientes en coma y mejorar la forma de cuidarlos. O también, detectar con la ayuda de electrodos cerebrales las intenciones de un sujeto, traducirlas en comandos efectivos, por ejemplo, para dirigir prótesis. Es una inmensa esperanza para los tetrapléjicos y los pacientes locked-in (literalmente los "encerrados en 
ellos mismos") que no pueden hablar ni hacer el menor gesto. La plasticidad cerebral permite a los pacientes adaptar su código neural a la máquina. A fines del 2006 se implantaron los primeros brazos biónicos comandados por el cerebro a un antiguo combatiente norteamericano.

- Escuchándolo se da uno cuenta del gran aporte de la imagenología. ¿No se corre el riesgo de que ella se vuelva más importante que la psicología?

Absolutamente no, la psicología sigue siendo central. En mi laboratorio, los que definen todos los experimentos para obtener las condiciones de estimulaciones más puras posibles y acceder así a los procesos elementales del pensamiento son psicólogos. La imagenografía cerebral y los otros métodos que surgen de la física o de las neurociencias solo son para nosotros herramientas, instrumentos cruciales. Y creo que los laboratorios de psicología que no posean estas máquinas se van a ver en dificultades. En el centro Neurospin, muy posiblemente desarrollaremos convenios y acogeremos experimentos externos.

- ¿Qué lo motiva a la fabricación de sus modelos psicológicos?

A mi manera de ver, la modelización debe jugar un rol esencial en psicología, a la vez para formular sus famosas leyes de establecimiento de los enlaces psiconeuronales, y para expresarlos bajo forma rigurosa, informática o matemática. Sin embargo, sigue siendo difícil desarrollar grandes teorías explicativas en psicología. Los modelos que he propuesto son más bien minimalistas, son capaces de explicar una o algunas tareas psicológicas clásicas. Se basan en tres puntos: a) parten de una organización de neuronas reales; b) tienen en cuenta la arquitectura del cerebro real; y c) simulan una verdadera tarea; se pone así en conexión el modelo con los datos empíricos.

Estos modelos se parecen, pero solamente en parte, al conexionismo que en los años 1980 constituían ya una interesante tentativa de modelización minimalista de la psicología. Si esta esperanza se perdió fue en parte a causa de la ausencia de una conexión con la realidad biológica. En la actualidad, la que desarrollamos es una verdadera biología teórica en dirección a la psicología que integra auténticas propiedades neuronales.

Encuentro muy excitante el momento en que nuestros diferentes conocimientos coagulan en la forma de una teoría unificada. Por ejemplo, se constituye actualmente una "ciencia de la lectura" que comienza a explicar cómo aprendemos a leer, qué redes están implicadas y por qué el "método global" no funciona.

- ¿Piensa usted como Jean-Pierre Changeux que hay una "Compatibilidad total entre el determinismo más absoluto y la aparente imprevisibilidad de nuestros comportamientos"? 
Incluso si pudiéramos disecarlos, nuestros mecanismos cerebrales son suficientemente complejos como para que sus resultados conserven un carácter no calculable y no previsible. Era un poco la idea de Baruch Spinoza cuando decía que los hombres se creían libres porque tenían conciencia de sus acciones, pero ignorantes de las causas que los determinan. Debemos aceptar que somos maquinitas magníficas. Y que incluso si nuestro comportamiento está determinado, no podemos preverlo. Me parece que en la comparación del hombre con la máquina, no es el hombre el que sale disminuido, sino ila máquina la que sale engrandecida!, apenas comenzamos a comprender de qué es capaz una máquina neuronal masivamente paralela y dotada de aprendizaje. Estos conocimientos tendrán numerosas repercusiones en informática y en la concepción de sistemas artificiales que nos ayudarán a superar los límites del cerebro humano.

- Usted compara la psicología con la física de los años 1930..., ¿por qué?

Nuestra disciplina está en plena expansión, como la física en aquella época. Es un mundo nuevo el que se abre. La psicología, a nivel internacional, está en un período de creatividad y exploración extraordinarias, con numerosos puentes lanzados en todos los sentidos, hacia las neurociencias, pero también la economía, la física, las matemáticas... Este carácter pluridisciplinario y que lo abarca todo, a veces es un poco desconcertante; se requiere mantener una coherencia. De alguna manera es una especie de i"edad heroica"! 